\title{
Rehabilitation of Stroke Patients - Effects of Early Intervention of Physical Therapy on Functional Outcome
}

\author{
Jebun Nessa ${ }^{1}$, Md. Abdul Khaleque², Shahanaz Begum ${ }^{3}$, AH Hamid Ahmed ${ }^{4}$, Mohammad \\ Shafiqul Islam ${ }^{5}$, Md. Afsan $^{6}$
}

\begin{abstract}
:
Context: Early initiation of rehabilitation procedures in stroke patients can enable greater return of neurological functions and prevents complication, thereby improves long term outcome and quality of life. Functional Independence measure (FIM) score is one of the commonest scale used to measure outcome.

Study design: Prospective type of study.

Place of study: Dept. of Physical Medicine and Rehabilitation, BSMMU.

Method: 48 acute onset first episode stroke patients were assessed Rehabilitation procedures started immediately after attending the Dept. According to a comprehensive rehabilitation plan physical therapy, speech therapy, occupational therapy was given and continued for 8 weeks, with proper education to the patient and the attendant.
\end{abstract}

Result: Outcome was measured and the result showed significant improvements ( $p$ value $<0.001$ ) in early treatment group of patients.

Key words: Stroke, FIM, Outcome.

\section{Introduction:}

Stroke is one of the leading causes of death and disability worldwide and more so in underdeveloped countries like Bangladesh, where health support system including rehabilitation is not expectedly available ${ }^{1}$.

Every year a significant number of stroke survivors are left with residual disabilities varying from mild to severe form ${ }^{2}$ which can be reduced by proper rehabilitation. Early initiation of rehabilitation procedures can enable greater return of neurological function and improves long term outcome and quality of life.

Stroke rehabilitation is a program designed to help the stroke victim to overcome the disability resulting from brain damage and to enable him or her at physical, psychological and social levels despite

1. Assistant Professor (c.c.), Department of Physical Medicine, Shaheed Suhrawardy Medical College, Dhaka

2. Assistant Professor, Department of Ophthalmology, BSMMU.

3. Associate Professor, Department of Anatomy, Shaheed Suhrawardy Medical College, Dhaka.

4. Assistant Professor, Department of Nephrology BSMMU.

5. Anaesthesiologist, Shaheed Suhrawardy Hospital, Dhaka

6. Associate Professor, Department of Pharmacology, Supporo Denal College, Uttara, Dhaka

Correspondence: Dr. Jebun Nessa the disability that remains after all spontaneous recovery from brain damage is ceased ${ }^{3}$.

According to the guideline for stroke rehabilitation, rehabilitation procedures should be started as soon as the diagnosis is established and life threatening problems are managed ${ }^{4}$. The objectives are to mobilize the patients and to promote resumption of self care activities ${ }^{4}$.

Proper rehabilitation of stroke patients includes early physical, occupational and speech therapy ${ }^{5}$. It is directed towards educating the patient and the family about the neurological deficit, how to prevent the complications of immobility (e.g. pressure sore, deep vein thrombosis, pneumonia, pulmonary embolism, muscle contracture etc.), to encourage and give instructions in overcoming the deficits ${ }^{5}$.

Patient progress and the rehabilitation outcome are assessed by different functional status measures; among them FIM (Functional Independent Measures) score is the most common ${ }^{2}$.

FIM score is an 18 item, 7 level scale of independent performance in
a. Self care
b. Sphincter control 
c. Transfer

d. Locomotion

e. Communication

f. Social cognition ${ }^{6}$.

The maximum score in this scale is 126 and the minimum is 18 .

This score is a reliable measure and can easily be administered for periodic assessment of changes in patient's performance ${ }^{6}$.

The stroke rehabilitation program entails accurate and repeated assessment of the residual disability and functional capacity of the patients. An early single assessment is of little value, since the pattern of recovery is variable ${ }^{7}$.

The study was carried out to see the nature of functional recovery in survivors of first episode stroke .The objective was to see the effects of rehabilitation and to compare the early intervention and late intervention group to determine functional outcome.

Materials and methods:

A prospective study was carried out on 48 stroke patients in the Department of Physical medicine and rehabilitation BSMMU, during the period of March to August 2003. The study period for each patient was 8 weeks. The patients were referred from Neuromedicine Department of BSMMU and Dhaka medical college.

Inclusion criteria:

1. First episode stroke.

2. Recent onset of stroke < 5weeks.

3. Patient having cerebral infarction and intracerebral hemorrhage.

4. Patients who were able to attend the Department of Physical Medicine and Rehabilitation for regular follow up.

Exclusion criteria:

1. Recurrent stroke.

2. Patients with complications e.g. recent M.I, angina or any other cardiac problem, Bronchial asthma etc.

3. Subarachnoid hemorrhage was excluded to obtain a more homogenous sample pathophysiologically.

\section{Methods:}

On attending the rehabilitation unit a careful thorough history was taken, the disabilities of patients were determined and their functional status was recorded in FIM sheet. In the FIM sheet functional status was measured on scale ranging from level 1(total assist) to level 7(complete independence). The patients were assessed whether they were dependent or not, if dependent how much assistance they need from the helper. Level 1 was put to complete dependent patients or those who were not testable e.g. unconscious.

A comprehensive rehabilitation plan was made considering the stage of stroke, consisting of different physical therapies described below.

1. IRR (Infra-red radiation) was applied to the affected side at a dose of 150 to 300 watts for 10 to 20 minutes once daily.

2. Exercises of different types (passive range of motion, stretching, active assistive, active resistive, proprioceptive neuromuscular facilitation, balancing exercise etc) were prescribed according to muscle power. After improving the muscle power gradually sitting balance, then standing balance exercise was prescribed. As the patient gained standing balance, gait training and coordination exercise was given using different walking aids e.g. Parallel bar, 4 point cane, 3 point cane, walker, walking stick etc.

3. Speech therapy was recommended in speech problems like dysphasia, dysarthria, apraxia of speech etc. The patients were asked to utter the commonly used words repeatedly several times daily e.g. their name, name of the relatives, in Muslim patients Allah, Bismillah etc. A sheet where common and easy words were written was supplied to the attendants so that the patients can practice.

4. Other supportive measures e.g. splint, brace etc. to prevent deformity and complications. Shoulder brace or elbow bag was applied to the affected shoulder during sitting position to prevent sublaxation of shoulder and developing frozen shoulder. Similarly cock-up splint, ankle- 
foot orthosis was prescribed if necessary to prevent deformities of wrist and foot respectively.

5. Later occupational therapy was given when required e.g. wheelchair, walking aids like walker, canes, stick etc, modified toilet and modified appliances for house hold works.

6. Moreover proper mouth care, skin care, bowel and bladder training for bed ridden patients were prescribed and maintained.

Each therapy session was provided by the same physiotherapist, one hour daily for 6 days in a week. The patients were given therapy for 2 weeks and advised to come for next follow up. The patient and at least one of the attendants were given education about task specific training with a goal regarding increasing range of motion of the joints of the affected limbs, transfer from bed to chair and wheelchair, control of posture, independent walking, bowel and bladder training etc. The attendant was educated properly to ensure that the patient would receive therapy regularly.

Follow up was done every 2 weekly and performances were recorded in FIM sheet.

When the patient first attended the rehabilitation unit, score was considered as the FIM admission score (FIM adm score). Follow up reports were put on the sheet 2 weekly and after 8 weeks study the final score was considered as FIM discharge score (FIM dis score). The difference between FIM admission score and FIM discharge score was considered as FIM gain and this gain was the functional outcome.

Statistical analysis was done by an unpaired t- test to determine the difference between the two groups, those who attended the rehabilitation unit earlier (within first two weeks of onset) and those who came after two weeks.

\section{Results:}

A number of 48 acute onset stroke patients were studied and detailed information was recorded on standard assessment form. The necessary data were processed and tabulated.

Onset admission interval is a term used in different international studies which is the interval between onset of disease and admission into hospital. In the present study there were no facilities for admission in the department of Physical Medicine and Rehabilitation, BSMMU. Some patients were treated as outpatient basis and some were referred from Neuromedicine indoor. So the time interval since the onset of stroke to first attending the rehabilitation unit was considered as onset admission interval (OAI).

Table -I shows the mean onset admission interval. Maximum number of patients (26) attended rehabilitation unit within first week of disease onset (54.14\%).12 patients (25\%) attended on 2nd week, 9 patients (18.74) on $3^{\text {rd }}$ week and 01patient (2.08) on $4^{\text {th }}$ week. The mean onset admission interval in total number of patients was $10 \pm 54$ days

Table - II shows mean FIM gain in patients of different age group. Maximum gain (mean) was 64, found among age group of 31- 40 years.

Table- III shows mean FIM gain in total number of patients $47.12 \pm 19.03$.

Table- IV shows FIM gain in patient receiving rehabilitation procedures in different weeks. Those who started in first week showed highest gain 56.04 \pm 16.05 .

Table - V shows comparison of FIM gain between two groups of patients receiving rehabilitation within first 2 weeks (52.82 \pm 1624$)$ and after 2 weeks (25.50 $\pm 12.29)$. Analysis by unpaired't' test showed significant difference ( $p$ value $<0.001$ ).

Table- VI shows functional gain in patients having higher FIM admission score $>36$ and lower FIM adm score $<36$. Among the total 48 patients, only 9 had higher FIM adm score $>36$ and their functional gain was $55.33 \pm 2.63$. Other 39 patients with lower score had functional gain $45.25 \pm 2066$. 
Table - I

Time elapsed after disease onset to starting of rehabilitation $(N=48)$

\begin{tabular}{lcccc}
\hline Weeks & No of patients & Percentage & Mean OAl in diff. weeks & Mean OAI total \\
\hline $1^{\text {st }}$ week & 26 & 54.14 & 5.44 days & $10 \pm 5.64$ days \\
$2^{\text {nd }}$ week & 12 & 25 & 10.25 days & \\
$3^{\text {rd }}$ week & 09 & 18.75 & 17 days & \\
$4^{\text {th }}$ week & 01 & 2.08 & 29 days & \\
\hline
\end{tabular}

Table - I shows different weeks and mean time interval in days since onset of stroke to starting of rehabilitation and the total mean OAI (Onset admission interval) was $10 \pm 5.64$ days.

Table - II

FIM gain in different age groups $(N=48)$

\begin{tabular}{lcccc}
\hline Age in years & No of patients & $\begin{array}{c}\text { FIM Adm score } \\
\text { (Mean) }\end{array}$ & $\begin{array}{c}\text { FIM score after 8 } \\
\text { weeks (mean) }\end{array}$ & $\begin{array}{c}\text { FIM gain } \\
\text { (mean) }\end{array}$ \\
\hline $31-40$ & 05 & 35.5 & 99.5 & 64 \\
$41-50$ & 15 & 19.83 & 48.16 & 28.33 \\
$51-60$ & 13 & 525.66 & 89 & 63.33 \\
$61-70$ & 09 & 39 & 88.75 & 49.75 \\
$71-80$ & 06 & 23.66 & 67.33 & 43.67 \\
\hline
\end{tabular}

Table -II shows mean FIM gain in patients of different age groups. Maximum mean FIM gain was 64 , found among age group of 31-40 years.

Table - III

Mean FIM gain in total no of patients ( $n-48)$

\begin{tabular}{cccc}
\hline No of patients & FIM Adm score (mean) & FIM score after 8 weeks (mean) & FIM gain (mean) \\
\hline 48 & $28.56 \pm 12.10$ & $75.06 \pm 25.55$ & $47.12 \pm 19.03$ \\
\hline
\end{tabular}

Table-III shows the mean FIM gain in total no of patients was $47.12 \pm 19.03$.

Table- IV

FIM gain in patients starting rehabilitation in different weeks (n-48).

\begin{tabular}{cccc}
\hline Weeks & FIM Adm (mean score) & FIM after 8 weeks(mean score) & FIM gain (mean score) \\
\hline $1^{\text {st }}$ week & $32.93 \pm 13.85$ & $87.89 \pm 22.04$ & $56.04 \pm 16.05$ \\
$2^{\text {nd }}$ week & $23.20 \pm 6.14$ & $67+18.97$ & $43.80 \pm 13.73$ \\
$3^{\text {rd }}$ week & $21.7 \pm 2.78$ & $47.67 \pm 12.68$ & $26 \pm 12.93$ \\
$4^{\text {th }}$ week & 22 & 43 & 21 \\
\hline
\end{tabular}

Table-IV shows FIM gain in patients starting rehabilitation in different weeks. Those who started in $1^{\text {st }}$ week showed highest gain $56.04 \pm 16.05$. 
Statistical analysis was done between the two groups by unpaired ' $t$ ' test. Very significant difference was found $(P<0.001)$.

Table - $V$ shows that the mean FIM gain in patients starting rehabilitation in duration up to 2 weeks was $52.82 \pm 16.24$ and in those who started rehabilitation after 2 weeks was $25.50 \pm 12.29$.
Table - V

FIM gain in patients starting rehabilitation in $1^{\text {st }} 2$ weeks and after 2 weeks. (n-48)

\begin{tabular}{lcc}
\hline Weeks & No of patients & FIM gain ( mean) \\
\hline Up to 2 weeks & 38 & $52.82 \pm 16.24$ \\
After 2 weeks & 10 & $25.50 \pm 12.29$ \\
\hline
\end{tabular}

Table - VI

FIM gain in patients having higher FIM Adm score (>36) and lower FIM Adm score (<36) (n-48)

\begin{tabular}{lcccc}
\hline $\begin{array}{l}\text { FIM Adm } \\
\text { score group }\end{array}$ & $\begin{array}{c}\text { No. of } \\
\text { patients }\end{array}$ & $\begin{array}{c}\text { FIM Adm } \\
\text { score }(\text { mean) }\end{array}$ & $\begin{array}{c}\text { FIM score } \\
\text { after } 8 \text { weeks (mean) }\end{array}$ & $\begin{array}{c}\text { FIM gain } \\
\text { (mean) }\end{array}$ \\
\hline Higher $>36$ & 9 & $49.33 \pm 12.53$ & $101.33 \pm 8.72$ & $55.33 \pm 2.65$ \\
Lower $<36$ & 39 & 23.774 .70 & $69 \pm 24.30$ & $45.23 \pm 20.66$ \\
\hline
\end{tabular}

Table -VI shows FIM gain in higher FIM Adm score group $>36$ and lower FIM Adm score group $<36$.

Among total 48 patients, 9 had higher FIM Adm score $>36$ and their functional gain was $55.33 \pm 2.65$.

39 patients had lower FIM Adm score $<36$ and their gain was $45.25 \pm 20.66$ which was less than the higher score group.

\section{Discussion:}

A number of controlled and uncontrolled randomized studies have suggested that rehabilitation program lead to an improvement in functional status that can not be attributed merely to spontaneous recovery. Ernst concluded after literature review that rehabilitation is preferable to spontaneous recovery, regardless of which physical therapy is chosen.

In the present study the mean onset admission interval (OAI) was $10 \pm 5.64$. Fiedler and Granger in USA found OAI was 13 days in their study ${ }^{8}$. Cunha et al ${ }^{4}$ found mean OAl was $15.30 \pm 9.47$ days.

The current study showed mean FIM admission score was 28.56. Inouye et $\mathrm{al}^{9}$ found FIM adm score $57 \pm 29$, Fiedler et $\mathrm{al}^{8}$ found FIM adm score was 63.1 in USA. The lower score in comparison to international studies was due to inclusion of only acute onset first episode stroke, where disability is more.
The follow up of this study was done on an outpatient basis, so final score was taken after 8 weeks i.e. 56 days, this score was considered equivalent to FIM discharge score(FIM dis score). In the present study mean FIM discharge score was 75.06 after 56days. Yazuver et $\mathrm{al}^{2}$ found that the FIM dis score was $86.7 \pm 24.2$ after length of stay (LOS) in hospital of $97.1 \pm 45.1$ days, Inouye et $\mathrm{al}^{9}$ found the score was $87 \pm 30$ after LOS of 121 days, Fiedler and Granger et al ${ }^{8}$ showed the score was 86.5 after LOS of 21 days.

The variations of the results were due to different length of stay in hospitals and due to low FIM adm score in this study.

In our study mean FIM gain was $47.12 \pm 19.33$ in total number of patients. The gain was $29 \pm 18$ by Inouye et $\mathrm{al}^{9}, 23.4$ by Fiedler et $\mathrm{al}^{8}$ and $22.9 \pm 11.9$ by Lew et al ${ }^{10}$ in their studies. The discrepancy was due to variation of admission and discharge score in different studies.

The maximum gain was found in those who attended the rehabilitation units earlier, in the first week (56.04 \pm 16 .05). Comparisons of those who attended within 2 weeks (52.82 \pm 16.24$)$ and after 2 weeks (25.50 \pm $12.29)$, prove significant improvement in early treatment group.

Some studies report that stroke recovery occurs fastest in the early months ${ }^{2}$. It is natural that 
patients, who enter rehabilitation program later, would show less change in their status of recovery 11. As FIM gain was found more in this study with less OAI, it indicates early rehabilitation can bring more functional gain.

\section{Conclusion:}

There are inadequate facilities for inpatient rehabilitation in our country and also lack of qualified personnel for domiciliary treatment of stroke patients. Stroke units with specially trained medical and nursing staff, coordinated multidisciplinary rehabilitation approaches and education program for patients and their families are needed in our country to achieve better outcome.

\section{References:}

1. Alam B et al : Stroke evaluation of risk factors. Bangladesh Journal of Neuroscience. 1999; 15(12): 14-18.

2. Yazuver G,Kucudeveci A,Arasil T,Ehlan A: Rehabilitation of stroke patients: clinical profile and functional outcome.Am J Phys Med Rehab, 2001; 80(4): 250-55.

3. Kaul S, Kumar CM. Rehabilitation of a stroke survivor, where do I go from here? In : Taly AB, NairKPS, Murali T, eds. Neurorehabilitation: Principles and practice. $2^{\text {nd }}$ ed. New Delhi: Ahuja Book Company, 2001:77-89.

4. Cunha IT, Lim PAC, Henson H, Monga T, Qureshy H, Protas EJ: Performance based gait tests for acute stroke patients. Am J Phys Med Rehab 2002; 81: 848-856.
5. SmithWS, Hauser SL, Easton JD. Cerebrovascular diseases. In Braunwald E, Fauci AS, Kasper DL, Hauser SL, Longo DL, Jemson $\mathrm{J} \mathrm{L}$, eds. Harrison's Principles of Internal Medicine. $15^{\text {th }}$ ed.USA:MCGraw-Hill Inc., 2001: 2369-91.

6. Granger CV. Health accounting- functional assessment of the long term patients. In: Kottke F J,Lehman J F, eds. Krusen's Handbook of Physical Medicine and Rehabilitation. $4^{\mathrm{TH}}$ ed. Philadelphia: W B Saunders Company, 1990: 270-281.

7. Nichols P J R,editor. Strokes. In: Rehabilitation Medicine. $2^{\text {nd }}$ ed, England: Butterworth \& Co Ltd, 1981: 159-81.

8. Fiedler RC, Granger C V, Russel CF: Uniform data system for medical rehabilitation: report of first admission for 1997. Am J Phys Med Rehab. 1998; 77: 444- 50.

9. Inouye $\mathrm{M}$, Hashimoto $\mathrm{H}, \mathrm{Mio} \mathrm{T}$, Sumino $\mathrm{K}$ : Influence on admission functional status on functional change after stroke rehabilitation. Am J Phys Med Rehab.2001; 80: 121-25.

10. Lew H L, Lee E, Date E S, Zeiner H : Influence of medical comorbidities and complications on FIM TM changes and length of stay during inpatient rehabilitation. Am J Phys Med Rehab 2002; 81: 830-837.

11. Wade D T,Skillbeck CE, Hewer R L : Predicting Barthel ADL score at 6 months after an acute stroke. Arch Phys Med Rehabil 1993; 74 : 1292-4. 